\title{
Migração interestadual e formação de capital humano no Brasil
}

\section{Paloma Santana Moreira Pais}

Professora Adjunta do Departamento de Administração e Economia

Universidade Federal de Lavras (UFLA)

\section{Leonardo Bornacki de Mattos}

Professor Adjunto do Departamento de Economia Rural

Universidade Federal de Viçosa (UFV)

\section{Evandro Camargos Teixeira}

Professor Adjunto do Departamento de Economia

Universidade Federal de Viçosa (UFV)

\section{Resumo}

A migração sempre esteve presente na história do Brasil e esta apresenta impactos sobre a acumulação de capital humano das diferentes regiões. Todavia, as pesquisas sobre a relação entre migração e capital humano são escassas no país, sobretudo por causa da predominância da mobilidade de pessoas com baixos níveis de qualificação, especialmente até o fim dos anos 1970 . Assim, neste trabalho são analisados os impactos da migração interestadual de indivíduos com diferentes níveis de qualificação sobre a formação de capital humano no local de origem do migrante. Para isso, utiliza-se um modelo de painel dinâmico, estimado com dados da PNAD, entre os anos de 2001 e 2013. Os resultados indicaram que a migração de pessoas com elevada qualificação incentiva a ampliação da frequência escolar na quinta série do ensino fundamental e no primeiro ano do ensino médio, enquanto a mesma não afeta a frequência ao primeiro ano do ensino superior. A migração de pessoas com baixa qualificação, porém, desestimula a frequência ao ensino superior, uma vez que os indivíduos residentes em áreas menos desenvolvidas não precisam se qualificar para obter maiores rendimentos, bastando migrar para áreas desenvolvidas com o nível de escolaridade que estes já possuem. Assim, a hipótese do brain gain não se confirma num contexto relacionado à frequência ao ensino superior.

Palavras-chave: migração interestadual, qualificação, capital humano.

\section{Introdução}

A literatura sobre o crescimento econômico considera que a acumulação de capital humano é um dos principais fatores que determinam o crescimento. A mobilidade deste capital entre as regiões pode afetar tanto a sua acumulação quanto o desenvolvimento econômico das diversas localidades. Neste sentido, Liu e Shen (2014) consideram que o influxo de pessoas com elevados níveis de educação pode acelerar a acumulação de capital humano, facilitando as atividades inovadoras e melhorando o potencial de crescimento endógeno das áreas receptoras.

Os primeiros trabalhos sobre a migração interna não se preocuparam com o nível de qualificação do migrante, visto que consideravam apenas a necessária transferência do excedente de trabalho do campo para as cidades, como Lewis (1954), Todaro (1969) e Harris e Todaro (1970). Entretanto, segundo Bildirici et al. (2005), em meados da década de 1960, quando a Inglaterra 
começou a perder um volume significativo de pessoas com maiores níveis de escolaridade para a América do Norte e outros países, houve o interesse na pesquisa sobre a migração de qualificados. Desde então, a literatura internacional tem estudado o fenômeno do brain drain (fuga de cérebros), que indica a transferência de capital humano, através da migração de indivíduos qualificados, de países em desenvolvimento para países desenvolvidos (BEINE, DOCQUIER, RAPOPORT, 2008). Beine et al. (2011) consideram qualificados aqueles que possuem educação pós-secundária. Di Maria e Lazarova (2012) assim chamam os que possuem educação terciária.

Os trabalhos nessa área consideram que a fuga de cérebros é responsável por alguns efeitos, sobretudo no país de origem do migrante. Alguns autores defendem que essa migração prejudica tal país, pela redução do estoque de capital humano e do bem-estar da população remanescente (GRUBEL, SCOTT, 1966; BHAGWATI, HAMADA, 1974).

Porém, na década de 1990, alguns autores como Mountford (1997), Vidal (1998) e Beine et al. $(2001,2008,2011)$ propuseram uma nova abordagem, que diz que esta migração estimula a formação de capital humano no país de origem, sendo chamada de brain gain (ganho de cérebros). Beine et al. (2008) defendem que, como o retorno à educação é maior no exterior (país de destino do migrante), as perspectivas de migração podem induzir mais pessoas a investirem em qualificação em seu país de origem, visando migrar no futuro. Tal ocorrência funcionaria como um efeito incentivo (chamado brain gain), que pode se sobrepor à perda real de pessoas qualificadas e provocar um ganho líquido no número de qualificados no país (benefical brain drain).

Num contexto de migração interna, como inexistem barreiras a essa mobilidade, os indivíduos são induzidos a buscarem maior remuneração ao capital humano adquirido deixando o seu estado de origem (BEZERRA; SILVEIRA NETO, 2008). Quando esses indivíduos possuem maiores níveis de escolaridade e migram para regiões mais desenvolvidas, pode-se tratar de uma fuga de cérebros, cujas consequências para os locais de origem podem ser semelhantes àquelas do quadro de migração internacional de qualificados.

Quando se analisa a pesquisa sobre as migrações no Brasil, verifica-se que pouca atenção tem sido dada ao nível de qualificação desse migrante. Segundo Diniz (1993), tal comportamento pode ser explicado pelo padrão de crescimento industrial observado no país, sobretudo até os anos 1970, cuja expansão se dera por meio das indústrias básicas, das indústrias de bens de consumo duráveis e pela expansão da fronteira agrícola nacional, que não exigiam altos níveis de escolaridade dos trabalhadores.

Nesse período, apenas Campino (1973) analisou os saldos migratórios estaduais, entre 1950 e 1970, considerando a mobilidade de indivíduos qualificados, para verificar os estados que apresentaram maiores perdas de capital humano e suas causas. Porém, devido ao baixo nível de escolaridade da população naquele período, o autor considerou qualificados os indivíduos com 
escolaridade mínima de nove anos de estudos. Os resultados indicaram que Maranhão, Piauí, Minas Gerais, Espírito Santo, São Paulo, Paraná, Santa Catarina e Rio Grande do Sul apresentaram perdas líquidas de pessoas com esse nível de qualificação.

Entretanto, Diniz (1993) ressalta que o surgimento das mudanças tecnológicas induziu a expansão de setores sustentados na ciência e na técnica, com reduzida demanda por recursos naturais, que criaram requisitos locacionais, como a presença de centros de ensino e pesquisa, de um mercado de trabalho profissional e de uma base educacional e cultural. Diante do fato que as oportunidades de migração interna podem alcançar um número significativamente maior de pessoas, devido ao menor número de barreiras e ao menor custo da mobilidade (NATALI, 2009) e do aumento das exigências de trabalhadores mais qualificados, algumas pesquisas nacionais voltaram à análise para a relação entre a migração e o capital humano.

Dentre estas pesquisas, verifica-se que os estudos buscam identificar o direcionamento dos fluxos de migração dessas pessoas, as características locacionais consideradas atrativas para os migrantes qualificados e constatar se há ou não fuga de cérebros interestadual no país.

Um destes trabalhos foi desenvolvido por Rigotti (2006), que investiga a dinâmica das migrações entre as mesorregiões do Brasil. O autor dividiu os migrantes em dois níveis de qualificação: indivíduos que possuem quinze anos ou mais de estudo e aqueles que têm até quatro anos de escolaridade. No primeiro grupo, ele observa que uma parcela significativa dos fluxos migratórios, entre 1995 e 2000, tem como origem as regiões metropolitanas (96\%), que também são os destinos preferenciais destes indivíduos. Quanto aos fluxos migratórios da população menos qualificada, Rigotti (2006) mostra que as regiões metropolitanas e as capitais também se destacam na atração e repulsão dessas pessoas, além de algumas cidades interioranas, como Campinas.

Mata et al. (2007) analisam quais as características das cidades as tornam atrativas para os migrantes qualificados, os quais possuem ensino superior completo ou incompleto. Os autores verificam que o dinamismo do mercado de trabalho, associado a um menor nível de desigualdade social e violência, além da proximidade ao litoral e condições climáticas menos rigorosas são determinantes da migração dessa mão de obra.

Bezerra e Silveira Neto (2008), por sua vez, verificam se existe fuga de cérebros no Brasil a partir da migração dos demais estados em direção a São Paulo. Seus resultados assinalam que as migrações destinadas a São Paulo não são dominados por pessoas qualificadas, exceto aquelas cujas origens são os estados do Rio de Janeiro e Rio Grande do Sul, e sim por trabalhadores com pouca ou nenhuma instrução. Além disso, os autores ressaltam que os estados com maior emigração em direção a São Paulo não registram perdas na produtividade pela emigração de qualificados. 
Diante disso, o presente estudo pretende fazer uma análise complementar àquela existente na literatura, na qual são avaliados os impactos da migração de indivíduos com diferentes níveis de qualificação sobre o capital humano no estado de origem.

Como ressaltado nos trabalhos de Beine et al. (2001, 2008, 2011), o incentivo a ampliar o capital humano dos indivíduos que pretendem mudar para outro país decorre do fato de que eles esperam obter um maior retorno no futuro pela qualificação adquirida ao mudar para o exterior. Entretanto, essa decisão ocorre num contexto de incerteza, pois a migração nem sempre é efetivada. Assim, nesse trabalho é analisado se tal efeito incentivo realmente existe num contexto de migrações interestaduais no Brasil, ou se existe um efeito desestímulo à obtenção de capital humano, decorrente da migração de pessoas com menores níveis de qualificação. Essa possibilidade foi ressaltada por Haas (2007), ao advertir que podem existir incentivos negativos para o aumento da escolaridade em sistemas nos quais predomina a migração de trabalhadores pouco qualificados.

\section{Referencial teórico}

Para analisar a relação entre migração e formação de capital humano, neste trabalho utilizase o modelo teórico proposto por Beine et al. (2011), que possui algumas pressuposições. Inicialmente, considera-se que cada país é habitado por indivíduos heterogêneos, que vivem durante dois períodos. No primeiro período, os indivíduos jovens trabalham e investem em capital humano e, no segundo período, os adultos dedicam todo o tempo ao trabalho. Outra hipótese é que a taxa salarial dos diferentes países varia em função da proporção de trabalhadores qualificados. Assim, se a migração de indivíduos qualificados afeta a proporção de educados do mercado de trabalho, ela poderá afetar o bem-estar dos habitantes remanescentes no país de origem dos migrantes.

Beine et al. (2011) assumem uma função de produção linear, considerando o trabalho em unidades de eficiência como o único insumo. Os trabalhadores com alta ou baixa qualificação são substitutos perfeitos, mas aqueles que possuem baixa qualificação ofertam uma unidade eficiente de trabalho, enquanto os que possuem alta qualificação oferecem $\sigma>1$ dessas unidades. Dessa forma, em cada período, o produto bruto doméstico é dado por:

$$
Y_{t}=w_{t} L_{t}
$$

em que $L_{t}$ é a força de trabalho total, em unidades de eficiência, e $w_{t}$ é a taxa de salário, sendo que $w_{t}$ é uma função crescente do número de adultos com alta qualificação $\left(H_{t}\right)$ remanescentes no país (com $w^{\prime}=\frac{\partial w_{t}}{\partial H_{t}}>0$ e $w^{\prime \prime} \neq 0$ para permitir retornos localmente crescentes). 
Adicionalmente, a utilidade esperada de cada trabalhador depende da renda no primeiro período e da renda esperada no segundo período ( $y_{1, t}$ e $\left.y_{2, t+1}\right)$.

$E\left[u_{t}\right]=\ln \left(y_{1, t}-\mu\right)+E\left[\ln \left(y_{2, t+1}\right)\right]$

em que $\mu$ é o nível de subsistência, o qual é nulo no segundo período.

Os autores consideram que os indivíduos jovens oferecem uma unidade de capital humano e recebem um salário $w_{t}$ de baixa qualificação, mas, se investirem parte de sua renda, eles acumulam capital humano. As pessoas são heterogêneas na aprendizagem e têm diferentes custos de educação (h), dependendo de suas habilidades. O custo da educação é uma proporção da taxa de salário. Para um agente do tipo $h$, o custo é $\alpha h w_{t}$, sendo que $\alpha$ é um parâmetro que captura o treinamento tecnológico e a política fiscal (quanto maior o subsídio à educação, menor será o $\alpha$ ). A variável $h$ é distribuída entre $[0,1]$. Os adultos dedicam todo o tempo no mercado de trabalho. Aqueles que possuem baixa qualificação recebem $w_{t}$ e os que possuem elevada qualificação recebem $\sigma w_{t}$.

Quando existe a possibilidade de migrar (subscrito $m$ ), os indivíduos jovens antecipam-na $\left(m_{t+1}\right)$ ao optarem pela educação. Beine et al. (2011) assumem que adultos com baixa qualificação não têm acesso à migração. Em um cenário de migração probabilística, em que $h_{m, t}$ é a proporção de jovens que optaram pela educação, a proporção ex-post de adultos qualificados remanescente é:

$$
H_{m, t+1}=\left\lfloor\left(1-m_{t+1}\right) h_{m, t}\right\rfloor /\left\lfloor 1-m_{t+1} h_{m, t}\right\rfloor
$$

Logo, para dado investimento em educação ex-ante, a taxa de migração $\left(m_{t+1}\right)$ reduz $H_{m, t+1}$.

Beine et al. (2011) consideram que a possibilidade de migrar afeta o retorno esperado pela escolaridade e induz o aumento da qualificação. Assim, considera-se $w^{*}$ a taxa de salário que representa o custo líquido de migração no país de destino do migrante e assume-se um prêmio de qualificação constante através dos países.

Nos países de elevada renda, onde a taxa do salário doméstico é maior ou igual a $w^{*}$, a migração não afeta as escolhas de educação. Nos países de renda baixa, indivíduos que investem em educação contemplam a possibilidade de migrar e tomar decisões em condições de incerteza. Assim, ex-ante, a expectativa de $m_{t+1}$ aumenta a proporção de jovens que investem em educação, criando a possibilidade de um ganho líquido nos países de origem. Se $w^{*}>w_{m, t+1}$, a educação é ótima quando maximiza a utilidade esperada, conforme se segue:

$$
\ln \left(w_{m, t}-\alpha h w_{m, t}-\mu\right)+m_{t+1} \ln \left(w^{*} \sigma\right)+\left(1-m_{t+1}\right) \ln \left(w_{m, t+1} \sigma\right)>\ln \left(w_{m, t}-\mu\right)+\ln \left(w_{m, t+1}\right)
$$

A proporção ex-ante de jovens educados é dada por: 
$h_{m, t} \equiv \frac{w_{m, t}-\mu}{\alpha w_{m, t}}\left\{\left[\sigma\left(\frac{w^{*}}{w_{m, t+1}}\right)^{m_{t+1}}-1\right] / \sigma\left(\frac{w^{*}}{w_{m, t+1}}\right)^{m_{t+1}}\right\}$

Se $\left(\frac{w^{*}}{w_{m, t+1}}\right)^{m_{t+1}}>1$, o nível crítico de qualificação aumenta com $m_{t+1}$ e mais indivíduos investem em educação.

Quando $w^{*}>w_{m, t+1}$, o mecanismo de incentivo à migração é dado por:

$\frac{\partial h_{m, t}}{\partial m_{t+1}}=\frac{w_{m, t}-\mu}{\alpha w_{m, t}}\left[\ln \left(\frac{w^{*}}{w_{m, t+1}}\right) / \sigma\left(\frac{w^{*}}{w_{m, t+1}}\right)^{m_{t+1}}\right]>0$

Beine et al. (2011) ressaltam que existe uma ligação entre o tamanho do incentivo e o nível de desenvolvimento. Nos países menos desenvolvidos, onde a taxa de salário é próxima ao nível de subsistência, as restrições de liquidez limitam as respostas aos incentivos. Porém, quanto menor o nível de desenvolvimento maior o incentivo, pois o prêmio da migração será elevado.

Entretanto, embora os indivíduos qualificados formem expectativas sobre a possibilidade de migrar, essa possibilidade deve ser considerada como potencialmente endógena. Nesse caso, Batista et al. (2012) observam que dois fatores podem ser responsáveis por essa endogeneidade. Em primeiro lugar, pode haver características individuais não observáveis que afetem a probabilidade de migrar no futuro e a propensão a obter um nível de escolaridade mais elevado. Adicionalmente, é provável que exista causalidade reversa, na qual a probabilidade do indivíduo migrar aumente quando ele possui uma maior escolaridade.

Beine et al. (2011) ressaltam que a diferença entre este modelo e aqueles propostos na literatura sobre a migração de indivíduos qualificados é a ênfase na forma como o nível de desenvolvimento do país de origem afeta a magnitude do mecanismo de incentivo à migração exante. Isso porque, nas regiões menos desenvolvidas, as restrições de liquidez podem ser um importante empecilho à mobilidade individual. Dessa forma, o modelo de Beine et al. (2011) supera a crítica de Commander et al. (2004) aos modelos de fuga de cérebros, na qual os autores afirmam que esses modelos não dão atenção à heterogeneidade dos países de origem dos migrantes.

Uma limitação do modelo é que ele considera apenas a relação entre a migração de pessoas qualificadas e a formação de capital humano, não avaliando o efeito da migração de pessoas com menores níveis de qualificação sobre o capital humano. Como não existe outro modelo que trate dessa relação na literatura, optou-se pela sua utilização por possuir o diferencial de considerar a heterogeneidade dos locais de origem dos migrantes, importante na análise da mobilidade no Brasil.

\section{Metodologia}


No que concerne à relação entre migração e capital humano, é preciso primeiramente selecionar uma variável para representar o capital humano. Neste trabalho, opta-se por utilizar a escolaridade formal, definida pelo número de anos de estudo, variável amplamente usada na literatura ${ }^{1}$.

Os trabalhos que analisam o impacto da migração sobre o capital humano, em geral, consideram apenas um nível de escolaridade. Beine et al. (2001, 2008, 2011) e Di Maria e Lazarova (2012), por exemplo, utilizam o nível terciário, ou seja, investigam o impacto da migração sobre a proporção de pessoas que possuem o ensino superior completo ou incompleto. Batista et al. (2012), por sua vez, analisam este impacto sobre a probabilidade de concluir nove anos de estudos.

Neste trabalho, entretanto, avalia-se os efeitos da migração sobre três séries de escolaridade, que são a quinta série ensino fundamental, o primeiro ano do ensino médio e o primeiro ano do ensino superior. Essas séries representam o primeiro ano dos três últimos níveis escolares do Sistema Brasileiro de Educação, com o regime de ensino fundamental de 8 anos. Neste trabalho utiliza-se este padrão porque a delimitação da amostra aos indivíduos com idade superior a 17 anos exclui aqueles que estão cursando ou concluíram o ensino fundamental no regime de 9 anos.

A opção por dividir o capital humano em níveis se justifica por alguns fatores. Inicialmente, conforme lembrado por Glick e Sahn (2000), a escolaridade alcançada é resultante de uma série de escolhas discretas, na qual as pessoas decidem se ingressam na próxima série ou se deixam a escola. De Leon e Menezes Filho (2002), identificam que, no Brasil, um percentual similar de estudantes abandonam as séries intermediárias de um mesmo nível escolar e há um aumento na evasão escolar quando o estudante conclui o último ano de cada ciclo. Gonçalves et al. (2008) também observam que a evasão é maior na quinta série, quando os alunos iniciam outra etapa no ensino fundamental.

Dado que o abandono escolar é maior ao se concluir um determinado nível, os estudantes precisam ser motivados a complementarem seus estudos, iniciando um novo ciclo. Diante disso, a migração e o sucesso profissional de uma pessoa qualificada pode ter um efeito positivo sobre a decisão individual de ampliar a escolaridade, sobretudo de iniciar um novo nível escolar.

Portanto, os modelos são estimados conforme a equação (7):

$\ln \left(\frac{h_{i, t}^{s}}{h_{i, t-1}^{s}}\right)=\alpha_{1 p} \sum_{p=1}^{T-1} m a q_{i, t-p}+\alpha_{2 p} \sum_{p=1}^{T-1} m m q_{i, t-p}+\alpha_{3 p} \sum_{p=1}^{T-1} m b q_{i, t-p}+\beta \ln \left(\frac{h_{i, t-1}^{s}}{h_{i, t-2}^{s}}\right)+\eta_{i}+\varepsilon_{i, t}$

em que $\ln \left(\frac{h_{i, t}^{s}}{h_{i, t-1}^{s}}\right)$ denota a taxa de crescimento da proporção de pessoas que estão frequentando a série $s$ entre os períodos $t$ e $t-1, \operatorname{com} t=2001, \ldots, 2013, s$ é a primeira série de cada ciclo $\left(5^{\mathrm{a}}\right.$ série do ensino fundamental, $1^{\circ}$ ano do ensino médio e $1^{\circ}$ ano do ensino superior); $\eta_{i}$ são os efeitos fixos

\footnotetext{
${ }^{1}$ Beine et al. (2001, 2008, 2011), Ritsilä e Haapanen (2003), Mackenzie e Rapoport (2006), Batista et al. (2012).
} 
específicos de cada estado, que capturam a influência sobre o nível de longo prazo da frequência naquela série e que são constantes ao longo do tempo; maq $q_{i, t-p}$ representa a taxa de migração dos trabalhadores com alta qualificação (que possui 12 anos ou mais de escolaridade) defasada em até $p$ períodos, com $p=1, \ldots, T-1 ; m m q_{i, t-p}$ representa a taxa de migração de trabalhadores com níveis de qualificação intermediários (entre 4 e 11 anos de estudo) do estado $i$ no período $t$ - $p$; $m b q_{i, t-p}$ representa a taxa de migração de trabalhadores com baixa qualificação (menos de 4 anos de estudo) do estado $i$ no período $t$ - $p$; $\beta$ é o parâmetro que mede a influência da frequência na respectiva série no ano anterior e $\varepsilon_{i, t}$ é o termo de erro da equação.

A variável $h_{i, t}^{s}$, por sua vez, representa a proporção entre os indivíduos oriundos do estado $i$ que estão frequentando a série escolar $s$ no período $t$ e os indivíduos do mesmo estado aptos a estarem cursando a mesma série escolar em $t+1$. Para selecionar esses indivíduos, são excluídos da amostra aqueles que possuem qualquer característica que os tornem inelegíveis para frequentarem essa série, conforme apresentado no Quadro 1 abaixo.

Quadro 1 - Indivíduos inelegíveis para cursar a série $s$

$S$

$$
\begin{gathered}
5^{\mathrm{a}} \text { série do } \\
\text { ensino } \\
\text { fundamental }
\end{gathered}
$$

- Menores de 11 anos;

- Que não estão frequentando a escola, mas já concluíram a $5^{\mathrm{a}}$ série;

- Que estão frequentando a escola e estão na $6^{\mathrm{a}}$ série ou em uma série superior;

- Maiores de 11 anos, cuja última série cursada foi inferior à $4^{\mathrm{a}}$.

- Menores de 15 anos;

- Que não estão frequentando a escola e já concluíram o $1^{\circ}$ ano do Ensino Médio;

$1^{\mathrm{o}}$ ano do ensino médio

- Que estão frequentando a escola e estão no $2^{\circ}$ ano do Ensino Médio ou em uma série superior;

- Maiores de 15 anos, cujo último ano estudado foi inferior à $8^{\mathrm{a}}$ série do Ensino Fundamental.

- Menores de 18 anos;

$1^{\mathrm{o}}$ ano do

Ensino

Superior

- Que não estão frequentando a escola e concluíram o $1^{\circ}$ ano do Ensino Superior;

- Que estão frequentando a escola, mas que estão no $2^{\circ}$ ano do Ensino Superior ou em um ano superior ao $2^{\circ}$;

- Maiores de 18 anos, cuja última série cursada foi inferior ao $3^{\circ}$ ano do Ensino Médio.

Fonte: Elaborado pela autora.

Da mesma forma que em Beine et al. (2011), a taxa de migração de trabalhadores com alta qualificação $\left(m a q_{i, t-p}\right)$ é definida como a relação entre o estoque de emigrantes com elevada qualificação que deixaram o seu estado de nascimento e o total de pessoas que possuem a mesma escolaridade nascidas no estado, ou seja, a soma dos residentes e emigrantes. Análise semelhante pode ser feita para definir as variáveis $m m q_{i, t-p}$ e $m b q_{i, t-p}$, que representam as relações entre os estoques de emigrantes com qualificação média e baixa do estado e o total de pessoas com os mesmos níveis de escolaridade nascidas nesse estado. 
Diante da indisponibilidade de dados sobre a localidade da formação do indivíduo, como ressaltado por Docquier e Marfouk (2006), é impossível fazer distinção entre os indivíduos que foram educados em seu estado de origem ou no destino. Por isso, os indivíduos que migraram na infância e se qualificaram no destino são tratados da mesma forma que aqueles que mudaram quando já estavam qualificados. Assim, são considerados migrantes de alta, média ou baixa qualificação as pessoas que possuem os níveis de escolaridade definidos anteriormente, que nasceram no estado $i$, mas se mudaram para o estado $j$.

De acordo com Beine et al. (2011), a estimação da equação (7) deve ser feita considerando duas questões. Primeiramente, deve-se analisar a natureza dinâmica da equação, pois a análise empírica da acumulação de capital humano deve permitir disparidades de longo prazo nesta variável entre as regiões. Para lidar com isso, o presente trabalho usa um modelo dinâmico.

Outra questão importante diz respeito à possível endogeneidade entre as taxas de migração de trabalhadores com diferentes níveis de qualificação com relação à mudança no capital humano. Nesse caso, Batista et al. (2012) observam que dois fatores podem ser responsáveis por essa endogeneidade. Em primeiro lugar, pode haver características individuais não observáveis que afetem a probabilidade de migrar no futuro e a propensão a obter um nível de escolaridade mais elevado. Adicionalmente, é provável que exista causalidade reversa, na qual a probabilidade do indivíduo migrar aumente quando ele possui uma maior escolaridade. Neste caso, são realizados os testes de Durbin (1954) e o de Wu e Hausman (Wu, 1974; Hausman, 1978) ${ }^{2}$ para conferir se as variáveis são realmente endógenas.

Diante disto, o presente trabalho utiliza o método de Painel Dinâmico proposto por Arellano e Bond (1991), que consegue tratar ambas as questões ao estimar os resultados. Com base neste método, os efeitos fixos da equação (7) são eliminados ao diferenciar a equação, conforme se segue:

$$
\Delta \ln \left(\frac{h_{i, t}^{s}}{h_{i, t-1}^{s}}\right)=\alpha_{1 p} \sum_{p=1}^{T-1} \Delta m a q_{i, t-p}+\alpha_{2 p} \sum_{p=1}^{T-1} \Delta m m q_{i, t-p}+\alpha_{3 p} \sum_{p=1}^{T-1} \Delta m b q_{i, t-p}+\beta \Delta \ln \left(\frac{h_{i, t-1}^{s}}{h_{i, t-2}^{s}}\right)+\Delta \varepsilon_{i, t}
$$

Entretanto, a diferenciação da equação (7) elimina o efeito fixo, mas não impede a correlação entre $\Delta \ln \left(\frac{h_{i, t-1}^{s}}{h_{i, t-2}^{s}}\right)$ e $\Delta \varepsilon_{i, t}$. Torna-se necessário utilizar variáveis instrumentais para a variável dependente diferenciada, sendo que Arellano e Bond (1991) sugerem que valores de $\ln \left(\frac{h_{i, t-1}^{s}}{h_{i, t-2}^{s}}\right)$ defasados em dois períodos ou mais são bons instrumentos para a equação (8).

O estimador de Arellano e Bond (1991) foi aprimorado por Arellano e Bover (1995) e Blundel e Bond (1998), ao identificarem que as variáveis defasadas em nível são instrumentos

\footnotetext{
${ }^{2}$ Testes de endogeneidade cuja hipótese nula é que a variável em consideração pode ser tratada como exógena.
} 
fracos quando os valores presentes das variáveis dependentes e explicativas estão fortemente correlacionados com seus valores passados. Para resolver o problema, os autores propõem que a utilização de instrumentos em primeira diferença para as equações em nível e instrumentos em nível para as equações em primeira diferença. Esse estimador ficou conhecido como system GMM. Blundel e Bond (1998) afirmam que o uso de restrições dos momentos adicionais confere um ganho de precisão para os coeficientes do system GMM, que possui melhor desempenho quando o parâmetro autorregressivo é moderadamente alto e o número de séries temporais é pequeno.

Entretanto, um possível problema que pode ocorrer com a estimação dos modelos difference e system GMM quando aplicados em amostras com poucas unidades cross-section é que os erros padrão assintóticos do estimador em dois estágios são viesados para baixo (ARELLANO, BOND, 1991; BLUNDEL, BOND, 1998). Porém, tal viés é substancialmente reduzido quando se emprega a técnica de correção da variância estimada para amostras finitas, proposta por Windmeijer (2005).

De acordo com Biondi e Toneto Jr. (2008), esse método permite tratar o problema das estimativas que possuem poucas unidades temporais e muitas unidades de seção cruzada, a existência de variável dependente defasada como regressor e de variáveis independentes que não são estritamente exógenas, a heterogeneidade individual invariante no tempo e a presença de heterocedasticidade e autocorrelação nas unidades individuais.

\subsection{Fonte de dados e variáveis utilizadas}

A análise empírica deste trabalho baseia-se nos dados da Pesquisa Nacional por Amostra de Domicílios (PNAD), do Instituto Brasileiro de Geografia e Estatística, entre os anos de 2001 e $2013^{3}$, totalizando 12 séries temporais. De acordo com Silva et al. (2002), o desenho amostral da PNAD possui aspectos que o definem como um 'plano amostral complexo', como a estratificação das unidades de amostragem, conglomeração ${ }^{4}$ e ajustes de pesos amostrais para calibração com totais populacionais conhecidos e probabilidades desiguais de seleção em um ou mais estágios. Assim, esses dados não podem ser considerados como se tivessem sido originados por amostras aleatórias simples com reposição, pois as medidas descritivas da população são influenciadas pelos pesos das observações. Por isso, consideram-se os pesos amostrais da PNAD no cálculo dos totais populacionais utilizados na construção dos dados agregados do modelo estimado.

O modelo empírico estimado neste trabalho contém uma amostra formada por 324 observações, constituída por 27 estados e 12 séries temporais das PNADs (de 2001 a 2013). A descrição das variáveis empregadas está apresentada na Tabela 1.

\footnotetext{
${ }^{3}$ Em 2010 não foi efetuada a pesquisa da PNAD, por se tratar de um ano de realização do Censo.

${ }^{4}$ Consiste na seleção de amostras em vários estágios, com unidades compostas de amostragem (SILVA; PESSOA; LILA, 2002).
} 
Tabela 1 - Descrição das variáveis empregadas no modelo de análise do impacto da migração sobre o capital humano

\begin{tabular}{|c|c|}
\hline Variável & Descrição \\
\hline $\begin{array}{l}\text { Taxa de crescimento da } \\
\text { proporção de pessoas que } \\
\text { frequentam a série } s\end{array}$ & $\begin{array}{l}\text { Logaritmo natural da diferença entre a relação da quantidade de } \\
\text { pessoas que frequentam a série } s \text { no ano } t \text { e a quantidade de } \\
\text { pessoas aptas a estar frequentando essa mesma série em } t+1\end{array}$ \\
\hline $\begin{array}{l}\text { Taxa de migrantes com alta } \\
\text { qualificação }\end{array}$ & $\begin{array}{c}\text { Logaritmo natural da quantidade de emigrantes do estado } i \text { que } \\
\text { possuem mais de } 11 \text { anos de escolaridade e o total de pessoas } \\
\text { nascidas em } i \text { com a mesma escolaridade }\end{array}$ \\
\hline $\begin{array}{l}\text { Taxa de migrantes com média } \\
\text { qualificação }\end{array}$ & $\begin{array}{c}\text { Logaritmo natural da quantidade de emigrantes do estado } i \text { que } \\
\text { possuem entre } 4 \text { e } 11 \text { anos de escolaridade e o total de pessoas } \\
\text { nascidas em } i \text { com a mesma escolaridade }\end{array}$ \\
\hline $\begin{array}{l}\text { Taxa de migrantes com baixa } \\
\text { qualificação }\end{array}$ & $\begin{array}{c}\text { Logaritmo natural da quantidade de emigrantes do estado } i \text { que } \\
\text { possuem menos de } 4 \text { anos de escolaridade e o total de pessoas } \\
\text { nascidas em } i \text { com a mesma escolaridade }\end{array}$ \\
\hline
\end{tabular}

Fonte: PNAD (2001 a 2013).

\section{Resultados e discussão}

Esta seção apresenta a análise dos impactos da migração interestadual de indivíduos com diferentes níveis de qualificação sobre a formação de capital humano, cujos resultados baseiam-se na estimação da equação (7). Especificamente, são estimadas as relações entre as migrações destes indivíduos sobre a taxa de crescimento da frequência escolar na quinta série do ensino fundamental, no primeiro ano do ensino médio e no primeiro ano do ensino superior. As variáveis de migração são consideradas estritamente exógenas, pois elas já estão incluídas no modelo empírico com, no mínimo, uma defasagem e os testes de endogeneidade de Durbin e de Wu e Hausman não rejeitaram a hipótese nula de exogeneidade das mesmas.

Embora os testes de Durbin e de Wu e Hausman não tenham rejeitado a hipótese de exogeneidade das variáveis de migração, a equação (7) ainda possui um componente endógeno, devido ao uso da variável dependente defasada como variável explicativa no modelo dinâmico. Por isso, como ressaltado na metodologia, o system GMM propõe que sejam utilizados instrumentos em nível para a equação em primeira diferença e instrumentos em primeira diferença para a equação em nível. Assim, para os resultados apresentados na Tabela 2, em todas as equações, o instrumento empregado para a equação em nível é a primeira diferença defasada da taxa de crescimento da frequência escolar ( $\Delta \mathrm{Tc}$ _freq $\left.\mathrm{t}_{-1}\right)$ e os instrumentos da equação em diferença são a segunda, terceira e quarta defasagens da variável dependente (Tc_freqt-2 e Tc_freq $\mathrm{T}_{-3}$ e Tc_freqt-4).

O uso dos instrumentos, entretanto, implica a necessidade de se aplicar o teste de Sargan (1958) para verificar a validade dos mesmos. Como apresentado na Tabela 2, verifica-se que a hipótese nula do teste de Sargan não foi rejeitada em nenhuma equação, indicando que as condições dos momentos estão corretas. Também é apresentado na Tabela 2 o teste de autocorrelação de 
Arellano e Bond (1991), o qual rejeitou a hipótese nula de ausência de autocorrelação dos erros de primeira ordem e não rejeitar essa hipótese para a segunda ordem, indicando que os modelos estão especificados de maneira adequada.

Tabela 2 - Impacto das migrações interestaduais de indivíduos com diferentes níveis de qualificação sobre a taxa de crescimento da frequência na $5^{\mathrm{a}}$ série do ensino fundamental, $1^{\mathrm{o}}$ ano do ensino médio e $1^{\circ}$ ano do ensino superior, 2001 a $2013^{1}$

\begin{tabular}{|c|c|c|c|}
\hline Variáveis & $\begin{array}{l}5^{\mathrm{a}} \text { série do ensino } \\
\text { fundamental }\end{array}$ & $\begin{array}{c}1^{\circ} \text { ano do ensino } \\
\text { médio }\end{array}$ & $\begin{array}{c}1^{\circ} \text { ano do ensino } \\
\text { superior }\end{array}$ \\
\hline Intercepto & $\begin{array}{c}3,245733^{* * * *} \\
(1,173122)\end{array}$ & $\begin{array}{l}3,829274^{* *} \\
(1,925089)\end{array}$ & $\begin{array}{l}-1,212013^{*} \\
(0,686414)\end{array}$ \\
\hline Ln_tc_freq(t-1) & $\begin{array}{c}-0,416829^{* * *} \\
(0,017090)\end{array}$ & $\begin{array}{c}-0,514578^{* * *} \\
(0,033619)\end{array}$ & $\begin{array}{c}-0,6765536^{* * * *} \\
(0,140785)\end{array}$ \\
\hline Ln_tc_freq(t-2) & & & $\begin{array}{c}-0,6034779^{* * * *} \\
(0,148154)\end{array}$ \\
\hline Ln_tc_freq(t-3) & & & $\begin{array}{c}-0,2182734^{* *} \\
(-0,218273)\end{array}$ \\
\hline Ln_maq(t-1) & $\begin{array}{l}1,355366^{* * *} \\
(0,401664)\end{array}$ & $\begin{array}{l}1,383037^{* * *} \\
(0,484975)\end{array}$ & $\begin{array}{c}-0,207072^{\mathrm{NS}} \\
(0,249081)\end{array}$ \\
\hline Ln_maq(t-2) & $\begin{array}{c}0,984274^{* * * *} \\
(0,311133)\end{array}$ & $\begin{array}{c}0,716438^{*} \\
(0,399964)\end{array}$ & \\
\hline Ln_mmq(t-1) & $\begin{array}{l}0,339277^{\mathrm{NS}} \\
(0,360747)\end{array}$ & $\begin{array}{l}0,611464^{\mathrm{NS}} \\
(0,606539)\end{array}$ & $\begin{array}{c}-0,074216^{\mathrm{NS}} \\
(0,261534)\end{array}$ \\
\hline Ln_mbq(t-1) & $\begin{array}{c}-0,5262778^{\mathrm{NS}} \\
(0,349394)\end{array}$ & $\begin{array}{l}-0,247126^{\mathrm{NS}} \\
(0,6476091)\end{array}$ & $\begin{array}{c}-0,007257^{\mathrm{NS}} \\
(0,174277)\end{array}$ \\
\hline Ln_mbq(t-2) & & & $\begin{array}{l}-0,500473^{*} \\
(0,259886)\end{array}$ \\
\hline $\begin{array}{c}\text { Wald } \\
\text { p-valor }\end{array}$ & $\begin{array}{l}615,82 \\
0,0000\end{array}$ & $\begin{array}{l}553,01 \\
0,0000\end{array}$ & $\begin{array}{c}69,94 \\
0,0000\end{array}$ \\
\hline $\begin{array}{c}\text { Arellano_Bond (AR1) } \\
\text { p-valor }\end{array}$ & $\begin{array}{l}-4,0025 \\
0,0001\end{array}$ & $\begin{array}{c}-3,9930 \\
0,0001\end{array}$ & $\begin{array}{c}-2,3530 \\
0,0186\end{array}$ \\
\hline $\begin{array}{c}\text { Arellano_Bond (AR2) } \\
\text { p-valor }\end{array}$ & $\begin{array}{c}-\mathbf{0 , 8 6 2 7} \\
0,3883\end{array}$ & $\begin{array}{l}0,1224 \\
0,9026\end{array}$ & $\begin{array}{l}0,2067 \\
0,8362\end{array}$ \\
\hline $\begin{array}{l}\text { Sargan } \\
\text { p-valor }\end{array}$ & $\begin{array}{l}23,9170 \\
0,4084\end{array}$ & $\begin{array}{l}24,3855 \\
0,3827\end{array}$ & $\begin{array}{l}12,2992 \\
\mathbf{0 , 5 8 2 3}\end{array}$ \\
\hline
\end{tabular}

Fonte: Resultados da pesquisa.

Nota: ${ }^{* * *}$ Significativo a $1 \%,{ }^{* *}$ significativo a $5 \%,{ }^{*}$ significativo a $10 \%$, ${ }^{\text {NS }}$ não significativo. Os valores entre parênteses referem-se aos erros-padrão. ${ }^{1}$ Em 2010 não houve a PNAD por se tratar de um ano de aplicação do Censo Demográfico.

Ao analisar a Tabela 2, verifica-se que os modelos estimados para as equações da taxa de crescimento da frequência escolar à quinta série e ao primeiro ano do ensino fundamental foram semelhantes. A equação estimada para o modelo da taxa de crescimento da frequência ao primeiro ano do ensino superior, porém, apresentou uma forma funcional diferente. Isso ocorreu porque, ao estimar o modelo com apenas uma defasagem para a variável dependente, o teste de Arellano e 
Bond apontou a existência de autocorrelação, a qual foi corrigida ao aumentar o número de defasagens e estimar a equação (8) utilizando esta forma funcional.

Os resultados apresentados nesta tabela ainda indicam que, em qualquer uma das equações, as defasagens da variável dependente foram estatisticamente significativas, indicando que existe uma dependência temporal da taxa de frequência escolar em todas as séries investigadas. Isto corrobora a utilização de um modelo dinâmico. O efeito negativo para esta variável pode ser explicado pelo comportamento declinante da taxa de crescimento da população em idade escolar.

Ao comparar estes resultados à literatura, tem-se que a pesquisa de Beine et al. (2011) foi a única a considerar a variável dependente defasada como variável explicativa nas estimações. O valor estimado pelos autores foi de $-0,074$, estatisticamente significativo a $1 \%$, sendo que os autores o atribuem a um processo de convergência do nível de educação entre os países.

Ao se considerar a taxa de migração de indivíduos com alta qualificação, verifica-se um impacto positivo e significativo desta sobre o crescimento da frequência escolar à quinta série do ensino fundamental e ao primeiro ano do ensino médio, enquanto a mesma não afeta a frequência ao primeiro ano do ensino superior. Para a equação referente à quinta série, verifica-se que, quando todas as demais variáveis permanecem constantes, um aumento de $1 \%$ na proporção de emigrantes qualificados em um determinado período é acompanhado por uma elevação de 1,36\% na taxa de crescimento da frequência escolar no período seguinte e de $0,98 \%$ nesta taxa dois períodos a frente. Em relação à equação da taxa de crescimento da frequência escolar ao primeiro ano do ensino médio, os mesmos aumentos são de $1,38 \%$ e $0,72 \%$, respectivamente.

Tais resultados indicam que a hipótese do brain gain é válida nestes contextos, ou seja, a migração de indivíduos qualificados funciona como um estímulo para que os indivíduos acima de dezessete anos invistam em capital humano, retornando à escola ou dando prosseguimento aos seus estudos na quinta série e no primeiro ano do ensino médio. O incentivo ocorre quando as pessoas visualizam o sucesso profissional alcançado por familiares ou conhecidos que, possuindo mais de onze anos de estudos, obtém maiores rendimentos ao deixarem o seu estado de origem. Então, tais pessoas investem tempo em escolaridade, objetivando alcançar tal êxito no futuro.

De acordo com a teoria da fuga de cérebros, a migração de indivíduos qualificados funciona como um incentivo à ampliação da escolaridade apenas quando esses fluxos têm como origem as áreas menos desenvolvidas e se direcionam a áreas mais ricas. Assim, ao analisar os dados da PNAD de 2013, verifica-se que 44,5\% dos migrantes com elevada qualificação que saíram das regiões Nordeste e Norte do país residem em São Paulo, Rio de Janeiro e Distrito Federal, estados que se destacam por apresentar elevados níveis de rendimento familiar. O sucesso profissional alcançado por tais indivíduos, portanto, incentiva as pessoas que permaneceram no estado de origem desses migrantes a continuarem estudando. Todavia, os emigrantes das regiões Sul e 
Sudeste também se deslocam para outros estados com elevados rendimentos, muitas vezes na própria região, o que também pode incentivar os demais habitantes a ampliarem o capital humano.

Ao confrontar tais evidências com a literatura internacional, verifica-se que Beine et al. (2001) e Di Maria e Lazarova (2012) obtêm coeficientes positivos e significativos para a taxa de migração de qualificados, cujos valores variam de 0,05 a 0,08 , usando métodos diferentes. Beine $e t$ al. (2011), por sua vez, dividem os migrantes qualificados com base na renda do local de origem dos mesmos e observam que apenas a migração de trabalhadores qualificados dos países com menores níveis de renda impacta o investimento em capital humano, com um coeficiente de 0,11. Batista et al. (2012) também alcançam estimativas significativas e que variam de 0,39 a 1,12 ao utilizar modelos de probabilidade para medir o impacto da própria probabilidade de migração futura sobre a probabilidade de completar o ensino secundário.

Apesar da limitada comparabilidade dos resultados das pesquisas internacionais com aqueles obtidos neste trabalho, observa-se que a migração de pessoas com alta qualificação também incentiva os indivíduos que não migraram a ampliarem seus níveis de capital humano, elevando a taxa de crescimento da frequência escolar na quinta série e no primeiro ano do ensino fundamental. Adicionalmente, como os fluxos de migração dentro do território nacional são maiores devido à ausência de barreiras à mobilidade interna, o incentivo a ampliar a escolaridade visando uma possível migração no futuro também deve ser superior.

No que concerne ao coeficiente desta variável no modelo relacionado à frequência ao primeiro ano do ensino superior, no entanto, verifica-se na Tabela 2 que este não foi significativo. Neste caso, a teoria do brain gain não se confirma no contexto de migração interestadual no Brasil. Uma possível explicação para este resultado é que, como os indivíduos com maiores níveis de escolaridade tendem a se concentrar nos estados de maior renda, não há incentivos para sua migração para outra localidade visando obter um rendimento semelhante ou ligeiramente superior.

Biene et al. (2011) realizam uma análise semelhante que pode justificar tal resultado. Os autores dividem os migrantes com base no país de origem, em migrantes qualificados de países ricos e de países em desenvolvimento, seguindo a classificação do Banco Mundial ${ }^{5}$. Ao estimar o modelo, os autores identificam que a taxa de migração de qualificados de países ricos não impacta a proporção de pessoas com treze anos ou mais de escolaridade do país de origem deste migrante, pois a renda desses indivíduos nos países ricos é maior ou igual àquela dos migrantes qualificados.

Adicionalmente, ao analisar os dados da PNAD de 2013, verifica-se que, dentre os indivíduos não migrantes com escolaridade maior ou igual a 12 anos de estudo, cerca 68,7\% residem nas regiões Sul e Sudeste. Por serem as regiões mais desenvolvidas do país, tais localidades

\footnotetext{
${ }^{5}$ Beine et al. (2011) empregaram a classificação do Banco Mundial do ano 2000, que dividia os países com base na renda, sendo considerados ricos os países cujo produto nacional bruto fosse igual ou superior a US $\$ 9.666,00$ e os demais foram chamados de países em desenvolvimento.
} 
concentram também uma maior quantidade de ofertas de trabalho que permitem ao indivíduo alcançar um maior rendimento, possibilitando a ele localizar-se na mesma cidade ou em outra no mesmo estado, mas que seja próxima ao local de residência dos seus familiares.

Além do fato dos indivíduos mais qualificados que não migraram estarem concentrados em regiões que apresentam maiores níveis de renda, conforme a teoria do brain gain, os indivíduos que não migraram residentes em áreas menos desenvolvidas se sentirão incentivados a estudar apenas quando os emigrantes com elevada qualificação se deslocarem para áreas mais desenvolvidas. Entretanto, ao analisar os dados da PNAD de 2013, identifica-se ainda que cerca de $90 \%$ dos emigrantes nascidos nas regiões Nordeste e Norte do país, as quais possuem menores níveis de renda, possuem até 11 anos de escolaridade. Os 10\% restantes, formados por emigrantes com alta qualificação (cerca de 951.240 pessoas), estão espalhados ao longo de todo o território formados por essas duas regiões. Dessa forma, a quantidade de pessoas com elevados níveis de qualificação que deixam o seu estado natal é pequena em relação ao restante dos migrantes, não sendo capaz de exercer um incentivo à ampliação da escolaridade para aqueles que permaneceram no local de origem, uma vez que a referência de migrante que essa população possui está associada aos indivíduos com baixos níveis de escolaridade.

É importante ressaltar que, diferentemente dos níveis anteriormente analisados, cujo acesso público é gratuito e garantido pela Lei No 9.394/96, a frequência ao ensino superior depende da aprovação no vestibular em uma universidade e do investimento financeiro, muitas vezes elevado, para a manutenção do estudante nesta universidade, seja com material, moradia, alimentação ou transporte. Por isso, embora possa existir o incentivo à ampliação da escolaridade para aqueles que objetiva migrar no futuro, suas restrições financeiras impedi-los de frequentar uma universidade.

Como ressaltado na introdução, historicamente a migração interestadual no país tem sido realizada por indivíduos com baixos níveis de escolaridade. Diante disso, o modelo empírico estimado neste trabalho também considera como a migração de indivíduos com qualificação média ou baixa poderia afetar o investimento em capital humano.

Dessa forma, quando se identifica o impacto das taxas de migração de pessoas com tais níveis de escolaridade sobre a taxa de crescimento da frequência à quinta série e ao primeiro ano do ensino médio, verifica-se na Tabela 2 que esses coeficientes não foram significativos. Isto indica que os indivíduos que possuem mais de 17 anos são indiferentes a aumentarem o seu estoque de capital humano, frequentando a quinta série do ensino fundamental, quando observam os resultados econômicos alcançados por migrantes cuja escolaridade máxima é o ensino médio completo.

Entretanto, ao confrontar tais resultados com os dados da renda familiar média obtida na PNAD de 2013, nota-se que o indivíduo não migrante apto a frequentar a quinta série possui um rendimento médio de $\mathrm{R} \$ 2.106$, 90, enquanto aquele que pode se matricular no primeiro ano do 
ensino médio obtém uma renda média familiar de $\mathrm{R} \$ 2.412,01$. Ao comparar tais rendimentos aos ganhos médios do migrante de baixa qualificação, que é de $\mathrm{R} \$ 1.967,41$, nota-se que não há estímulo à ampliação do capital humano, uma vez que a renda presente daqueles indivíduos supera a obtida por esse migrante. Entretanto, tais rendimentos são inferiores àquele obtido pelo migrante que possui qualificação média em $\mathrm{R} \$ 811,25$ e $\mathrm{R} \$ 506,14$. Todavia, essa diferença que representa uma espécie de "prêmio" pela migração pode ser insuficiente para incentivar tais pessoas a migrarem, uma vez que a migração envolve custos. Adicionalmente, como ressaltado por Beine et al. (2011), mesmo que esse aumento na renda seja atrativo, as restrições de liquidez existentes nos locais menos desenvolvidos, podem limitar as pessoas a responderem aos incentivos.

Ao analisar o impacto da migração de pessoas com qualificação média sobre a taxa de crescimento da frequência ao primeiro ano do ensino superior, os resultados não foram significativos. Por razões semelhantes às descritas anteriormente, este resultado pode indicar que o "prêmio" pela migração não é suficiente para incentivar o aumento do capital humano.

Entretanto, ao analisar a migração de pessoas com baixos níveis de qualificação, observa-se na Tabela 2 que esta variável impacta negativamente a taxa de crescimento da frequência ao primeiro ano do ensino superior, porém este efeito ocorre apenas na segunda defasagem da variável, indicando que é necessário um período de tempo para que a migração de desqualificados desestimule a aquisição de capital humano. Tal evidência confirma a hipótese levantada por Haas (2007), de que nos países marcados pela migração de trabalhadores pouco qualificados, como é o caso do Brasil, pode existir incentivos negativos para o aumento da escolaridade. Isso porque os resultados econômicos alcançados pelos migrantes desqualificados podem ser considerados satisfatórios para os indivíduos que almejam migrar no futuro, não sendo necessário investir na acumulação de capital humano.

Esse resultado pode ser confirmado ao analisar os dados da PNAD de 2013. Neste caso, a renda familiar média de um indivíduo não migrante que reside nas regiões Norte e Nordeste e possui 11 anos de escolaridade, ou seja, aquele que está apto a frequentar o primeiro ano do ensino superior, é de $\mathrm{R} \$ 2.303,14$. O rendimento médio familiar de um migrante com baixa qualificação e que tenha saídos destas regiões para morar nas regiões Sudeste e Sul do país, é de R 2.119,34. Dessa forma, como o migrante, mesmo possuindo um nível de escolaridade consideravelmente menor que este indivíduo que não migrou, possui um rendimento semelhante ao obtido por este, isto faz com que o não migrante sinta-se desestimulado a ampliar o seu nível de escolaridade, uma vez que ele pode migrar com o seu atual nível de qualificação e obter uma renda de $\mathrm{R} \$ 3.230,53$, valor $40 \%$ superior ao obtido em seu estado natal.

Todavia, é importante ressaltar que, embora o modelo teórico empregado nesta pesquisa considere que a migração é uma variável importante na determinação da escolaridade, Barros et al. 
(2001) considera que o baixo nível de investimento em capital humano no Brasil está associado à disponibilidade e qualidade dos serviços educacionais, ao ambiente familiar, à atratividade do mercado de trabalho e à disponibilidade de recursos na família. Tais variáveis também podem afetar a resposta dos indivíduos ao incentivo dado pela migração, uma vez que, se a família reside num local com difícil acesso às escolas e universidades ou se a escassez de recursos financeiros exige que as pessoas sejam inseridas no mercado de trabalho precocemente, as condições presentes com as quais tais pessoas se deparam limitam as suas perspectivas de melhoria resultante do aumento da qualificação visando à migração no futuro.

\section{Conclusão}

Diante dos resultados apresentados nesta pesquisa, constata-se que a migração de pessoas altamente qualificadas tem incentivado a ampliação da frequência escolar dos indivíduos aptos a frequentarem a quinta série do ensino fundamental e o primeiro ano do ensino médio. Isso porque tais indivíduos constatam a possibilidade de alcançar rendimentos consideravelmente superiores se continuarem estudando até alcançar o nível de qualificação daquele migrante, quando poderão efetuar a sua mudança para o mesmo destino. Entretanto, o prêmio que estes indivíduos poderiam obter quando comparam seus ganhos atuais àqueles obtidos pelos migrantes de qualificação média ou baixa é pequeno ou mesmo negativo, o que faz com que tais pessoas sejam indiferentes a aumentar o nível de capital humano por causa daquelas migrações.

A taxa de crescimento da frequência ao primeiro ano do ensino superior, no entanto, não é influenciada pela migração de pessoas com elevado nível de qualificação. Tal resultado decorre do fato de que os indivíduos que não migraram e que possuem o ensino médio completo estão mais concentrados em estados que já têm rendimentos médios mais elevados e, por isso, não necessitam migrar para conseguir tais rendimentos. Adicionalmente, as taxas de migração de pessoas altamente qualificadas de locais menos desenvolvidos são baixas, não sendo capazes de influenciar a população remanescente a aumentar a escolaridade. Ainda que essas taxas motivem os indivíduos a ampliarem seus níveis de qualificação, considerando que o aumento na renda no destino seja atrativo, se os rendimentos da família forem próximos aos valores necessários para a sua sobrevivência, as restrições financeiras podem limitar a resposta aos incentivos, uma vez que a acesso ao ensino superior envolve uma série de gastos, mesmo quando a universidade é pública.

Contudo, a mobilidade de pessoas com baixos níveis de qualificação é um fator de desestímulo à ampliação do capital humano dos residentes do estado de origem que possuem o ensino médio completo. Tal evidência ocorre porque o rendimento obtido pelos indivíduos que possuem esse nível de escolaridade e moram em regiões menos desenvolvidas, como Norte e Nordeste, é muito próximo àquele obtido pelos migrantes com baixos níveis de qualificação que 
mudaram para as regiões Sul e Sudeste. Isto faz com que a migração desses indivíduos no presente já seja capaz de aumentar substancialmente os seus rendimentos, não sendo necessário ampliar o nível de escolaridade para efetuar a mudança no futuro.

Este trabalho apresenta algumas limitações, sobretudo no que concerne aos dados utilizados. A PNAD é uma pesquisa que fornece um retrato da população na data em que foi entrevistada, não sendo possível identificar a situação econômica do indivíduo antes da migração ou a localidade no qual ele alcançou o presente nível de escolaridade. Além disso, a PNAD também não acompanha o mesmo indivíduo ao longo do tempo, sendo necessário, então, utilizar dados agregados dessa fonte. Entretanto, por ser uma das principais fontes de dados sobre a migração, além de conter outras informações sobre a situação social e econômica dos indivíduos, optou-se pela sua utilização.

Para pesquisas futuras sugere-se que a análise do impacto da migração sobre o capital humano seja feita em um nível municipal. Isso permitiria identificar se existem diferenças significativas entre esses resultados e aqueles obtidos para os estados, uma vez que os incentivos advindos da mobilidade de um indivíduo para uma cidade mais próxima podem ser maiores, uma vez que a distância entre a origem e o destino e os custos envolvidos na mudança são inferiores.

\section{Referências}

ARELLANO, M.; BOND, S.R. Some tests of specification for panel data: Monte Carlo evidence and an application to employment equations. The Review of Economic Studies, v. 58, n. 2, p. 277 297, 1991.

ARELLANO, M.; BOVER, O. Another look at the instrumental variable estimation of error components models. Journal of Econometrics, v. 68, n. 1, p. 29-51, 1995.

BARROS, R. P.; MENDONÇA, R. SANTOS, D. D.; QUINTAES, G. Determinantes do desempenho educacional no Brasil. Pesquisa e Planejamento Econômico, v. 31, n. 1, p.1-42, 2001.

BATISTA, C.; LACUESTA, A.; VICENTE, P. C. Testing the 'brain gain' hypothesis: Micro evidence from Cape Verde. Journal of Development Economics, v. 97, n. 1, p. 32-45, 2012.

BEINE, M.; DOCQUIER, F.; RAPOPORT, H., Brain Drain and Economic Growth: Theory and Evidence, Journal of Development Economics, v.64, n.1, p. 275-289, 2001.

BEINE, M., DOCQUIER, F. e RAPOPORT, H. Brain Drain and Human Capital Formation in Developing Countries: Winners and Losers. The Economic Journal, vol.118, p. 631-652. 2008.

BEINE, M.; DOQUIER, F.; ODEN-DEFOORT, C. A panel data analysis of the brain gain. World Development, v. 39, n. 4, p. 523-532, 2011.

BEZERRA, F. M.; SILVEIRA NETO, R. M. Existe fuga de cérebros no Brasil? Evidências a partir dos censos demográficos de 1991 e 2000. EconomiA, v.9, n.3, p. 435-456, 2008. 
BHAGWATI, J.; HAMADA, K. The brain drain, international integration of markets for professionals and unemployment: A theoretical analysis. Journal of Development Economics, v. 1, p. 19-42, 1974.

BILDIRICI, M.; ORCAN, M.; SUNAL, S.; AYKAÇ, E. Determinants of human capital theory, growth and brain drain: An econometric analysis of 77 countries. Applied Econometrics and International Development, v. 5, n. 2, p.c109-140, 2005.

BIONDI, R. L.; TONETO JR., R. Regime de metas inflacionárias: os impactos sobre o desempenho econômico dos países. Estudos Econômicos, v. 38, n. 4, p. 873-903, 2008.

BLUNDELL, R. W.; BOND, S. R. Initial conditions and moment restrictions in dynamic panel data models. Journal of Econometrics, v. 87, n. 1, p. 115-143, 1998.

CAMPINO, A. C. C. A migração de pessoas qualificadas no período 1950/70. Pesquisa e Planejamento Econômico, vol. 3, n. 4, p. 1091 a 1102, 1973.

COMMANDER, S.; KANGASNIEMI, M.; WINTERS, L. A. The brain drain: A review of theory and facts. Brussels Economic Review, v. 47, n. 1, p. 29-44, 2004.

DE LEON, F. L. L; MENEZES FILHO, N. A. Reprovação, avanço e evasão escolar no Brasil. Pesquisa e Planejamento Econômico, v. 32, n. 3, p. 417-452, 2002.

DI MARIA, C.L; LAZAROVA, E. A. Migration, human capital formation, and growth: An empirical investigation. World Development, v. 40, n. 5, p. 938-955, 2012.

DINIZ, C. C. Desenvolvimento poligonal no Brasil: Nem desconcentração nem contínua polarização. Nova Economia, v. 3, n. 1, p. 35-64, 1993.

DOCQUIER, F.; MARFOUK, A. International migration by educational attainment, 1990-2000 (release 1.1). In OZDEN, C.; SCHIFF, M. (Eds.). International migration, remittances and development. NewYork: McMillan and Palgrave, 2006.

DURBIN, J. Errors in variables. Review of the International Statistical Institute, v. 22, n. 1/3, p.23-32, 1954.

GLICK, P.; SAHN, D. E. Schooling of girls and boys in a West African country: The effects of parental education, income, and household structure. Economics of Education Review, v. 19, n. 1, p. 63-87, 2000.

GONÇALVES, M. E. Análise de sobrevivência e modelos hierárquicos logísticos longitudinais: uma aplicação à análise da trajetória escolar ( $4^{\mathrm{a}}$ a $8^{\mathrm{a}}$ série - ensino fundamental). 2008, 143 p. Tese (Doutorado em Demografia) - Universidade Federal de Minas Gerais, UFMG/CEDEPLAR, Belo Horizonte, MG, 2008.

GRUBEL, H. B.; SCOTT, A. D. The international flow of human capital. The American Economic Review, v. 56, n. 1/2, p. 268-274, 1966.

HAAS, H. Migration and Development: A theoretical perspective. COMCAD Working Papers, $\mathrm{n}$. 29, 2007. 82 p. 
HARRIS, J.; TODARO, M. Migration, unemployment and development: Two sector analysis. The American Economic Review, v. 15, n. 1, p. 126-142, 1970.

HAUSMAN, J. A. Specification tests in econometrics. Econometrica, v. 46, n.6, p. 1251-1271, 1978.

LEWIS, W. A. Economic Development with Unlimited Supplies of Labor. The Manchester School, v. 22, n. 2, p. 139-191, 1954.

LIU, Y.; SHEN, J. Spatial patterns and determinants of skilled migration in China, 2000-2005. Papers in Regional Science, v. 93, n. 4, p. 749-771, 2014.

MACKENZIE, D.; RAPOPORT, H. Can migration reduce educational attainment? Evidence from Mexico. World Bank Policy Research Working Paper, n. 3952, 2006. 42 p.

MATA, D.; OLIVEIRA, C. W.; PIN, C.; RESENDE, G. Quais características das cidades determinam a atração de migrantes qualificados? Revista Econômica do Nordeste, v. 38, n. 3, p. 502-514, 2007.

MIYAGIWA, K. Scale economies in education and the brain drain problem. International Economic Review, v. 32, n. 3, p. 743-759, 1991.

MOUNTFORD, A., Can a brain drain be good for growth in the source economy? Journal of Development Economics, v.53, n.2, 287-303, 1997.

NATALI, C. Linkages between Internal and international migrations: Policy implications for development. In: XVI Conference Urban-Rural Linkages and Migration, Plenary Session... Dortmund, September of 2009.

RIGOTTI, J. I. R. Geografia dos fluxos populacionais segundo níveis de escolaridade dos migrantes. Estudos Avançados, v. 20, n. 57, 237-254, 2006.

RITSILÄ, J.; HAAPANEN, M. Where Do the Highly Educated Migrate? Micro-Level Evidence from Finland. International Review of Applied Economics, v. 17, n. 4, p. 437-448, 2003.

SARGAN, J. D. The estimation of econometric relationships using instrumental variables. Econometrica, v. 26, n. 3, p. 393-415, 1958.

SILVA, P. L. N.; PESSOA, D. G. C.; LILA, M. F. Análise estatística de dados da PNAD: Incorporando a estrutura do plano amostral. Ciência e Saúde Coletiva, v. 7, n. 4, p. 659-670, 2002.

TODARO, M. A model of labour migration and urban unemplyment in less developed countries. American Economic Review, v. 59, n. 1, p. 138-148, 1969.

VIDAL, J. P. The effect of emigration on human capital formation. Journal of Population Economics, v.11, n.4, p. 589-600, 1998.

WINDMEIJER, F. A finite sample correction for the variance of linear efficient two-step GMM estimators. Journal of Econometrics, v. 126, n. 1, p. 25- 51, 2005.

WU, D. M. Alternative tests of independence between stochastic regressors and disturbances: Finite sample results. Econometrica, v. 42, n. 3, p. 529-546, 1974. 